\title{
Matematik Öğretiminin Biçimlendirici Değerlendirme Sürecinde Kahoot! ve Plickers \\ Uygulamalarının İncelenmesi ${ }^{1}$ \\ Yılmaz ZENGIN ${ }^{2}$, Mehmet BARS ${ }^{3}$ Ömer ŞiMŞEK ${ }^{4}$
}

\section{Öz}

Bu çalışmanın amacı Kahoot! ve Plickers yazılımlarının matematik öğretiminin biçimlendirici değerlendirme sürecinde kullanımının matematik öğretmeni adaylarının görüşleri doğrultusunda incelemektir. Nitel araştırma yaklaşımı ile desenlenen bu çalışma 15 matematik öğretmeni adayı ile yürütülmüş̧ür. Bilgisayar destekli matematik öğretimi dersi kapsamında dört hafta süresince Kahoot! ve Plickers'ın biçimlendirici değerlendirmede kullanımına yönelik uygulamalar yapılmıştır. Uygulamaların sonunda açık uçlu sorulardan oluşan bir görüş formu ile veriler toplanmıştır. Verilerin analizinde içerik analizi yöntemi kullanılmıştır. Matematik öğretmeni adaylarının Kahoot! ve Plickers'ı uygulamaları sonucundaki görüşlerine göre, bu yazılımların matematik öğretiminin biçimlendirici değerlendirme sürecinde kullanılmasında uygulanabilir olması, değerlendirmeyi kolaylaştırması, ayrıntılı ve anlık veri analizi olanağı sağlayarak zamandan tasarruf olanağı sunması gibi olumlu katkıları olduğu belirlenmiştir. Dersin sürecini ve değerlendirmeyi oyunlaştıran bu uygulamalar, öğretmen adaylarının matematik öğretiminde teknoloji kullanımına yönelik olumlu tutum geliştirmelerine yardımcı olmuştur. Katılımcılar, bu yazılımların kullanımıyla öğrencilerin derse katılımının ve motivasyonlarının önemli ölçüde artacağını ifade etmişlerdir. Ayrıca bu uygulamalar eğitimde teknoloji entegrasyonu yeterliği sağlayabilmektedir. Çalışmada Kahoot!'un teknolojik alt yapı gerektirmesi önemli bir sınırlılık olarak görülmektedir. Bu yazılımların matematik öğretmeni adaylarının yetiştirilmesinde ve matematik öğretmenlerinin hizmet içi eğitimlerinde uygulamalı olarak ele alınması önerilmektedir.

Anahtar sözcükler: Kahoot!, Plickers, biçimlendirici değerlendirme, matematik öğretimi

\footnotetext{
${ }^{1} \mathrm{Bu}$ araştırma Dicle Üniversitesi Bilimsel Araştırma Projeleri Koordinatörlüğü tarafından desteklenmiş ve ICITS 2017'de sözlü bildiri olarak sunulmuştur.

${ }^{2}$ Yrd. Doç. Dr., Dicle Üniversitesi, Ziya Gökalp Eğitim Fakültesi, Matematik ve Fen Bilimleri Eğitimi Bölümü, yilmazzengin@outlook.com

${ }^{3}$ Arş. Gör. Dr., Dicle Üniversitesi, Ziya Gökalp Eğitim Fakültesi, Eğitim Bilimleri Bölümü, mehmetbars21@gmail.com

${ }^{4}$ Arş. Gör. Dr., Dicle Üniversitesi, Ziya Gökalp Eğitim Fakültesi, Bilgisayar ve Öğretim Teknolojileri

Eğitimi Bölümü, omarsimsek@gmail.com
} 


\title{
Investigation of Using Kahoot! and Plickers in Formative Evaluation Process in Mathematics Teaching
}

Accepted by 2017-09-25

\begin{abstract}
The purpose of this study is to investigate pre-service mathematics teachers' views about using Kahoot! and Plickers in formative evaluation in mathematics teaching. The qualitative study is conducted with 15 pre-service mathematics teachers. Implementations towards using Kahoot! and Plickers in formative evaluation in mathematics took four weeks in a computer assisted mathematics instruction course. At the end of the implementations, qualitative data were gathered with an open ended questionnaire. Content analysis was used in data analyses. The views of preservice mathematics teachers revealed that these software have many advantages in formative evaluation such as being practical in formative evaluation of mathematics teaching, facilitating the evaluation, providing detailed and instant data analysis and saving time. According to the participants these software applications help them to develop positive attitudes using technology in mathematics instruction and gamify both the teaching and learning processes and the evaluation. The participants stated that by using these software, the engagement and motivation of students were increased significantly. Besides using the software provided competence of technology integration in education. It was reported that Kahoot!'s requiring technology infrastructure is an important limitation. Consequently, it is suggested that these software should be handled practically in pre-service mathematics teacher education and in service training of mathematics teachers.
\end{abstract}

Keywords: Kahoot!, Plickers, formative evaluation, mathematics teaching 


\section{Giriş}

Matematik öğretiminin ayrılmaz bir parçası olan değerlendirme tüm öğrencilerin matematik öğrenmesine büyük ölçüde katkı sağlamaktadır. Değerlendirme sadece öğretimin sonunda uygulanan bir testten ziyade öğretmenlerin öğretimsel kararlar almasını sağlamakta ve tüm öğrencilere derin ve nitelikli bir matematik öğrenme firsatı sunmaktadır. Bu şekilde öğretimi şekillendirmek veya içerik hakkında karar vermek için öğretmenlere yardımcı olan değerlendirmeler genellikle biçimlendirici değerlendirme olarak ifade edilmektedir (National Council of Teachers of Mathematics [NCTM], 2000). Matematik öğrenme ve öğretme süreci devam ederken öğrencilerin öğrenmelerini ve gelişimlerini belirlemeyi amaçlayan biçimlendirici değerlendirme ile öğretmenler, öğrencilerin öğrenemediği matematiksel kavram ve konular hakkında zengin öğrenme ortamları hazırlama firsatı bulmaktadır. Bu değerlendirmelerde amaç eksikleri belirleme olup not verme özelliği taşımaz. Biçimlendirici değerlendirmenin öğrencilerin matematik dersindeki gelişimlerini sağlayacak etkinliklere temel oluşturulması amaçlanmaktadır (Baki, 2008). Bu değerlendirmenin temel işlevi her bir ünitedeki öğrenme eksikliklerini ve güçlüklerini belirlemek ve belirlenen eksiklik ve yetersizliklerin giderilmesi için her bir öğrenciye önerilerde bulunmaktır. Özellikle matematik gibi ön koşul ilişkilerin öğrenilmesinin gerekli olduğu derslerde biçimlendirici değerlendirmenin yapılmaması ile alt basamaklardaki bilgi ve becerileri kazanmamış öğrencilerin üst sıralardaki davranışları kazanması güçleşmektedir (Tekin, 2010a). Ön koşul becerilerinin önemli olduğu matematik dersinde öğretiminin planlanması aşamalarında, davranışlar arasındaki ilişkilere önem verilmesi ve bu ilişkilerin ortaya çıarılması gerekmektedir (Baykul ve Tertemiz, 2004). Ön koşul beceriler bir zincirin halkası gibi önemlidir. Zincirin halkasında meydana gelecek kopmalar öğrenmeyi olumsuz etkilemektedir. Öğrencilerin eksikliklerinin giderilerek sonraki etkinliklere geçilmesi daha etkili bir öğrenme sürecinin oluşmasına imkân tanımaktadır (Atılgan, 2011). En çok zorlanılan derslerin başında gelen matematik alanında (Emenalo, 1984; Herzig, 2002) biçimlendirici değerlendirmenin öğrenme ve öğretme sürecinin ayrılmaz bir parçası olarak ele alınması gerekliliği ortaya çıkmıştır.

Biçimlendirici değerlendirme matematik öğrenme ve öğretme sürecinde bireysel ve spesifik amaçların gerçekleştirilmesine yardımcı olmaktadır (Ginsburg, 2009). Matematik öğretiminde biçimlendirici değerlendirmenin kullanılması öğrencilerin başarısına olumlu yönde katkı sağlamaktadır (Tempelaar ve diğ., 2012; Tekin, 2010b). Ayrıca biçimlendirici 
değerlendirme öğrencilerin matematiğe yönelik tutumunu ve edindikleri bilgilerin kalıcılığını olumlu yönde etkilemektedir (Tekin, 2010b). Matematik öğretiminde biçimlendirici değerlendirmenin bu olumlu katkılarının yanı sıra öğrencilere kendi öğrenme süreçlerinin farkında olmalarını sağlamaktadır. Öğretmenlere ise öğrencilerinin düşüncelerinin analizini yapmaya olanak tanımaktadır (Wang, Martin, Lambert ve Pugalee, 2014). Etkili bir matematik öğretiminde, sıklıkla kullanılması gereken biçimlendirici değerlendirme öğrencilerde var olan kavram yanılgılarının ortaya çıkarılmasını sağlamaktadır (McIntosh, 1997; Wiliam, 1999). Basit matematiksel kavram yanılgıları tespit edilerek giderilmediği takdirde daha sonraki kavramların öğrenilmesi sürecinde problemlere yol açmaktadır (Bull, Jackson ve Lancaster, 2010). Biçimlendirici testler kullanılarak öğrencilerin kavramları nasıl anladıkları, kural ve formülleri nasıl uyguladıkları ve çözümleri nasıl yapılandırdıkları incelenebilmekte ve öğrencilerin sahip oldukları matematiksel kavram yanılgıları tespit edilebilmektedir (Mevarech, 1983). Matematik öğrenme ve öğretme sürecinde biçimlendirici değerlendirme amacıyla kullanılan testler belirli bir ünite için düzenlenir ve öğrenmede güçlük çekilen yerleri, öğrenme eksikliklerini ve yanlış öğrenmeleri tespit etmek için kullanılır. Uygulanan test sonucunda öğrencilere dönütler verilir, ek etkinlikler yapılır ve öğretim süreci bu dönütler doğrultusunda yeniden tasarlanabilir (Tekin, 2010a). Bu tür değerlendirmeler matematik öğrenme ve öğretme sürecinde sürekli kullanılarak öğrencilerin bireysel olarak izlenmesini sağlar (Baki, 2008). Aynı şekilde Black ve Wiliam (2010) kısa testlerin sık sık kullanılmasının önemini vurgulamış, testlerdeki soruların seçiminde dikkatli olunması gerektiği ve soruların en iyilerinin belirlenerek diğer öğretmenlerle bunların paylaşıldığı bir kaynak oluşturması gerektiğini ifade etmişlerdir. Bilgi ve iletişim teknolojilerinin öğrenme ve öğretme sürecinde kullanılmasının yaygınlaşması sonucunda öğretmenler kolaylıkla biçimlendirici testleri hazırlama, sik sık uygulama yapma ve paylaşma firsatı yakalayabilmektedir. Teknolojinin matematik derslerinde biçimlendirici değerlendirmede kullanılmasıyla öğrencilere anında ve bireysel dönütler verilebilmektedir (Stacey ve Wiliam, 2013). Özellikle matematik gibi soyut, karmaşık ve algılanması zor bir derste (Rosnick, 1981) biçimlendirici değerlendirmenin bilişsel ve duyuşsal açıdan sağladığı pozitif katkıların teknolojiyle zenginleştirilerek öğrenme ortamına yansıması öğretmenler ve öğrenciler için bu dersin yapılandırılmasında ek bir destek sunabilir. Biçimlendirici değerlendirme öğretmenler için zaman alıcı ve ders dışı çalışma yapılması gereken bir uygulama olduğundan (Tekin ve Özdemir, 2014) teknolojinin bu süreçte kullanımı önem arz etmektedir. 
Geleneksel yaklaşımlar yeniliği gölgelemekte, öğretmenlerin yeni bilgi ve beceriler edinmesini ve öğrenme ortamında değișen rollerini benimsemelerini geciktirmektedir (Ersoy, 2005). Geleneksel anlayışın ötesinde yapısalcı bir anlayışla bilgi ve iletişim teknolojilerinin matematik derslerinde kullanılması verimli ve işlevsel öğrenme ortamları oluşturabilir (Baki, 2002). Bu nedenle biçimlendirici değerlendirmenin matematik derslerine yansıması yapısalcı anlayışa uygun bir çerçevede güncel bilgi ve iletişim teknolojileriyle zenginleştirilebilir. Teknolojiyle zenginleştirilmiş ortamlar matematik öğretmenlerine zaman açısından katkı sağlayarak değerlendirmenin sık sık öğrenme ortamında kullanılmasına yardımcı olabilir. Öğretim ortamında kullanılan teknolojilerden beklenen faydanın sağlanabilmesi için nitelikli yazılımların seçilerek kullanılması gerekmektedir (Kazu ve Yavuzalp, 2008). Öğrenme ortamında uygun teknolojilerin kullanılmasıyla öğrencilerin derse katılımları artmakta ve hızlı bir şekilde öğrencilerin öğrenmelerinin değerlendirilmesi gerçekleşebilmektedir (Johns, 2015). Mobil araçlarla kullanılabilen web tabanlı öğrenci yanıt sistemleri (ÖYS) bu teknolojilere örnek olarak verilebilir (Richardson, Dunn, McDonald ve Oprescu, 2015). Bu gibi teknolojilerin katkılarını sınıf ortamına taşıyan, ücretsiz ve oyun tabanlı bir uygulama olan Kahoot!, biçimlendirici değerlendirmede kullanılabilir. Öğretmenlere çoktan seçmeli soruları oluşturma, paylaşma, paylaşılan quizleri kullanma veya düzenleyerek uygulayabilme firsatı sunan Kahoot!, öğrencilerin hesap açmalarına gerek olmadan mobil cihaz veya bilgisayar kullanarak sorulara verdikleri doğru yanıtları cevaplama süresine göre puanlamaktadır (Siegle, 2015). Öğretmen rehberliğinde öğrenciler birer yarışmacı rolünde oyunu oynamaktadırlar. Derse katılımı ve motivasyonu artıran Kahoot!, öğretmene biçimlendirici değerlendirme için görsel ve ayrıntılı bir veri kaynağı oluşturup oyun sonunda hemen ayrıntılı rapor sunmaktadır (Wang, 2015). Kahoot! uygulamasının sınıf ortamına taşınması için öğrencilerin internet bağlantısının olduğu akıllı telefon, tablet veya bilgisayarları kullanmaları gerekmektedir. Buna karşın Plickers bu sınırlılığı ortadan kaldırmaktadır. Birbirinden farklı kartların öğrencilere dağıtıldığı ve öğretmenin mobil telefonun kamerası ile öğrencilerin kartlarını taradı̆̆ı Plickers uygulaması öğretmene anlık görsel grafikler sunarak biçimlendirici değerlendirmenin yapılmasına anlık dönütler vererek katkı sunmaktadır (Howell, Tseng ve Colorado-Resa, 2017). Plickers uygulamasının kullanımının kolay olduğu, gerçek zamanlı değerlendirme yapma imkânı sunduğu ve öğrencilere motive edici bir perspektif sağladığı belirlenmiştir (López García, 2016). Bu uygulamaların özellikle de matematik gibi zorluk düzeyi yüksek bir derste biçimlendirici değerlendirme sürecini 
zenginleştirmede kullanımının öğretmene ve öğrencilere alternatif bir ortam sunabilmesi bakımından önemli olduğu düşünülmektedir. Bu uygulamaların olumlu katkılarının öğrenme ortamına taşınmasında öğretmenler anahtar görev üstlenmektedir (Baylor ve Ritchie, 2002). Özellikle matematik öğretiminde, öğretmenin yeni teknolojik uygulamalar hakkındaki bilinç düzeyi ve inançları, bu teknolojilerin okula taşınmasını doğrudan etkilemektedir. $\mathrm{Bu}$ nedenle matematik öğretmenlerinin bilişsel araçları ve yeni bilgi ve iletişim teknolojilerini nasıl algıladıkları ve değerlendirdikleri, yeni bir uygulamanın sınıflara taşınmasında göz ardı edilmemesi gereken önemli ölçütlerden biridir (Ersoy, 2005). Bu değerlendirmeler 1şı̆̆ında çalışmanın amacı Kahoot! ve Plickers yazılımlarının biçimlendirici değerlendirmede kullanımını geleceğin öğretmenlerinin görüşleri doğrultusunda incelemektir.

\section{Yöntem}

Kahoot! ve Plickers yazılımlarının matematik öğretiminin biçimlendirici değerlendirme sürecinde kullanılmasını, matematik öğretmeni adaylarının görüşleri doğrultusunda inceleyen bu araştırma, nitel araştırma yaklaşımı benimsenerek gerçekleştirilmiştir. Araştırmada, Kahoot! ve Plickers yazılımlarının biçimlendirici değerlendirmede kullanımı öğretmen adaylarının görüşleri çerçevesinde detaylı bir şekilde incelenmektedir.

\section{Çalışma Grubu}

Çalışmanın katılımcılarını üçüncü sınıftaki 15 matematik öğretmeni adayı oluşturmaktadır. Katılımcılar kolay ulaşılabilir durum örnekleme metodu ile belirlenmiştir. $\mathrm{Bu}$ metot araştırmacılara, katılımcılara ulaşmada etkili ve pratik olanaklar sunmaktadır (McMillan ve Schumacher, 2010). Katılımcılar bu çalışmadan önce, bilgisayar destekli matematik öğretimi dersi kapsamında matematiksel yazılımların öğrenme ve öğretme sürecinde kullanımına yönelik uygulama yapmış ve yazılımlar ile temel düzeyde dinamik materyaller hazırlamışlardır. Katılımcıların Kahoot! ve Plickers yazılımlarını kullanmaya yönelik herhangi bir deneyimi bulunmamaktadır. Katılımcıların 11'i kadın 4'ü erkektir. 
Tablo 1. Katılımcıların Bilgisayar, Internet ve Mobil Cihazları Kullanma Düzeyleri

\begin{tabular}{llll}
\hline & $\begin{array}{l}\text { Tamamen } \\
\text { yeterli }\end{array}$ & Yeterli & $\begin{array}{l}\text { Kismen } \\
\text { yeterli }\end{array}$ \\
\hline İnternet kullanma düzeyi & 3 & 6 & 6 \\
Bilgisayar kullanma düzeyi & 2 & 6 & 7 \\
$\begin{array}{l}\text { Mobil cihazları (cep telefonu, tablet) kullanma } \\
\text { yeterliği }\end{array}$ & 6 & 7 & 2 \\
\hline
\end{tabular}

Katılımcıları betimlemek adına uygulama öncesinde mobil cihaz, internet ve bilgisayar kullanma düzeyi ile ilgili katılımcılara bir form dağıtılmıştır. Buna göre katılımcılara ait özellikler Tablo 1'de verilmiştir. Katılımcıların yarısından fazlası bilgisayar kullanma yeterliklerini ve internet kullanma düzeyini "Yeterli" ve "Tamamen yeterli” şeklinde ifade etmiştir. Öğretmen adaylarının sadece ikisi mobil cihazları kullanma yeterliğini "Kısmen yeterli" olarak belirtmiştir. Çalışma grubunda yer alan öğretmen adaylarının yarısından fazlası kendilerini bilgisayar, internet ve mobil cihaz kullanımında yeterli buldukları görülmektedir.

\section{Veri Toplama Araci}

Çalışmada veri toplama aracı olarak açık uçlu sorulardan oluşan bir görüş formu kullanılmıştır.

Görüş formu hazırlanırken üç araştırmacı ilgili literatür ve çalışmanın amacı çerçevesinde 13 sorudan oluşan taslak bir görüş formu hazırlamış ve pilot olarak iki matematik öğretmenine uygulamıştır. Elde edilen dönütler doğrultusunda toplam sekiz açık uçlu sorudan oluşan bu forma son hali verilmiştir. Nihai form öğretmen adaylarının Kahoot! ve Plickers yazılımlarının biçimlendirici değerlendirme bağlamında görüşlerini incelemek için kullanılmıştır. Öğretmen adaylarına uygulanan örnek açık uçlu sorulardan biri "Yapılan uygulamalar, matematik ögretiminde biçimlendirici değerlendirme sürecinde teknoloji kullanımı becerilerinizi nasıl etkiledi?" "şeklindedir.

\section{Verilerin Analizi}

Uygulamalar sonucunda elde edilen veriler içerik analizine tabi tutulmuştur (Yıldırım ve Şimşek, 2011). Tümevarımcı bir çözümleme anlayışıyla yapılan analiz, iki araştırmacı tarafından ayrı ayrı incelenmiş ve kodlar ortaya çıkarıldıktan sonra birlikte değerlendirilmişsir. Ayrıca iki araştırmacı 
kod ve kategori oluşturma sürecinde araştırmanın diğer yazarı ile birlikte tartışmış ve süreç sonunda elde edilen kategoriler bulgular kısmında sunulmuştur.

\section{Süreç}

Uygulama, her hafta dört ders saati olmak üzere toplam dört hafta sürmüştür. Kahoot! ve Plickers uygulamaları öncesinde öğretmen adayları bilgisayar destekli matematik öğretimi dersinde, matematiksel yazılımlar aracılı̆̆ıla kavramların çoklu temsillerini incelemeye olanak sunan problemler oluşturmuş, kavramsal ve dinamik sorular hazırlamış, üç boyutlu geometrik yapılar inşa etmiş, her seviyede soru hazırlama ve değerlendirme süreci için temel matematiksel sembolleri kullanma deneyiminde bulunmuştur. Araştırmacılar tarafından dört hafta süresince 15 matematik öğretmeni adayına toplam 16 saat Kahoot! ve Plickers yazılımlarının yapısı ve işlevleri açıklanarak bu yazılımların biçimlendirici değerlendirmede kullanımına yönelik örnek uygulamalar yaptırılmıştır. Uygulama sürecinde ders kapsamında ele alınan içerik Tablo 2'de ayrıntılı bir şekilde verilmiştir.

Tablo 2. Uygulama Süreci

\begin{tabular}{|c|c|}
\hline 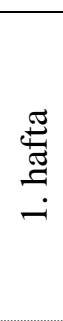 & $\begin{array}{l}\text { Biçimlendirici değerlendirmenin matematik öğrenme ve öğretme sürecindeki yerinin tartış1lmas } \\
\text { Biçimlendirici değerlendirmede bilgi ve iletişim teknolojilerinin kullanımı } \\
\text { Kahoot!'un genel tanıtımı } \\
\text { Kahoot!'u kullanmak için https://getkahoot.com/ sitesine üye olma } \\
\text { Sınav (Quiz), eşleştirme (Jumble), tartışma (Discussion) ya da anket (Survey) gibi etkinlikleri } \\
\text { tanıma } \\
\text { Araştırmacıların hazırladığı Kahoot! uygulanması }\end{array}$ \\
\hline $\begin{array}{l}\underset{\mathscr{J}}{\mathscr{E}} \\
\text { i }\end{array}$ & $\begin{array}{l}\text { Ögretmen adaylarının Kahoot! ile Sınav (Quiz), eşleştirme (Jumble), tartışma (Discussion) ya da } \\
\text { anket (Survey) gibi etkinlikleri hazırlamaları } \\
\text { Öğretmen adaylarının hazırladıkları etkinlikleri sınıfta sunmaları } \\
\text { Öğretmen adaylarının hazırladıkları etkinlik sonrasında sonuçlarını (Get Results) analiz etme } \\
\text { Lise matematik öğretim programında bir kazanıma ait Kahoot! etkinliği hazırlama ve paylaşma }\end{array}$ \\
\hline 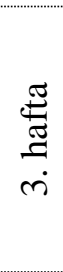 & $\begin{array}{l}\text { Plickers yazılımının neden tercih edildiği ve öğrenme ortamındaki pedagojik potansiyelini } \\
\text { tartışma } \\
\text { Mobil cihaza Plickers kurulumu } \\
\text { Plickers hesabında klasörler oluşturma ve bu klasörlere sorular ekleme } \\
\text { Mobil cihazın kamerası ile Plickers uygulaması } \\
\text { Sonuçların dağılımlarını grafikler şeklinde inceleme }\end{array}$ \\
\hline 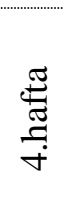 & $\begin{array}{l}\text { Ögretmen adaylarının Kahoot! ve Plickers uygulamalarını sınıfa yansıtmaları (Şekil la) } \\
\text { Görünüş geçerliğine sahip GeoGebra ile hazırladıkları soruları Kahoot! ve Plickers ortamına } \\
\text { aktarma ve paylaşma } \\
\text { Biçimlendirici değerlendirmede Kahoot! ve Plickers uygulamalarının pedagojik yönünü tartışma } \\
\text { Veri toplama aracının uygulanması }\end{array}$ \\
\hline
\end{tabular}


Uygulama sürecinde her hafta sonunda bir sonraki hafta için Kahoot! veya Plickers yazılımlarıyla ilgili çeşitli etkinlikler tasarlamaları ve sınıfta arkadaşlarına sunmaları istenmiştir. Öğretmen adayları uygulamalar süresince grup çalışmalarında bulunmuş ortak etkinlikler de hazırlamışlardır. Lise matematik öğretim programındaki kazanımlar çerçevesinde içerikler hazırlanmış ve sunulmuştur.

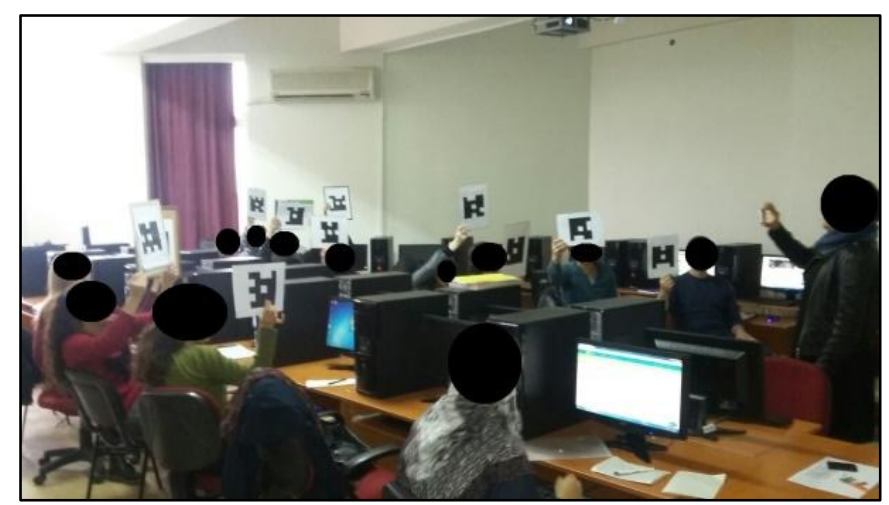

Şekil 1a

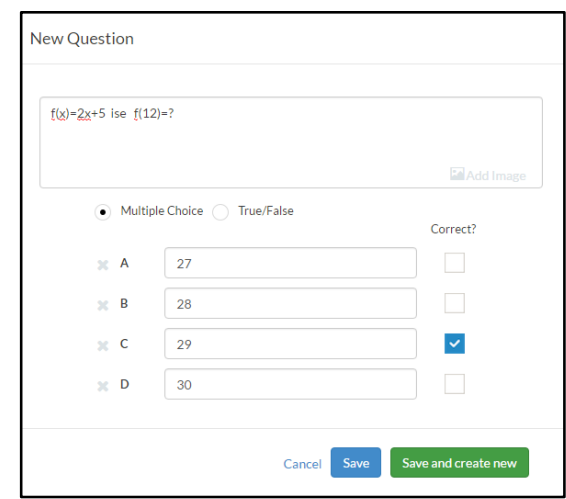

Sekil 1b

Şekil 1. Sınıf ortamı (1a) ve Plickers uygulamasındaki soru (1b)

Dersler iki veya üç araştırmacı tarafından yürütülmüş. Araştırmacılar öğretmen adaylarına sürekli dönütler vermeye çalışmıştır. Öğretmen adayları grup çalışmalarında ikili informal işbirlikli gruplarda çalışmıs, etkinliklerini hazırlamış ve sınıf ile paylaşmıştır.

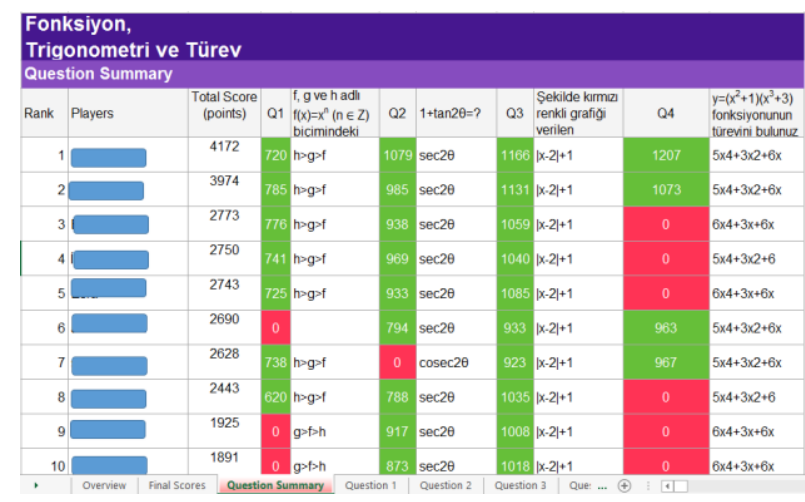

Şekil 2. Örnek Kahoot! sonuç çıktısı

Kahoot! ile yapılan dört soruluk bir uygulamada, öğretmen adaylarının sorulara verdikleri doğru ve yanlış yanıtları gösteren sonuç çıktısı Şekil 2'de verilmiştir. Kahoot! uygulaması her sorunun sonrasında doğru ve yanlış yanıtların sayısını göstererek anlık bir geri bildirim sunmakta; uygulama sonunda ise ayrıntılı bir sonuç dosyası oluşturarak biçimlendirici 
değerlendirmeye olanak sağlamaktadır. Araştırmacılar dersin genelinde bu uygulamalara rehberlik rolünü üstlenmiş ve öğretmen adaylarının kendi tasarladıklarını paylaşmalarını desteklemişlerdir.

\section{Bulgular}

Yapılan çözümlemeler sonucunda öğretmen adayları Kahoot! ve Plickers yazılımlarının çoğunlukla biçimlendirici değerlendirme açısından kullanımına ilişkin görüş bildirmişlerdir. Tablo 3'de bu yazılımların biçimlendirici değerlendirmeye ilişkin kodları bulunmaktadır.

Tablo 3. Kahoot! ve Plickers'ın Biçimlendirici Değerlendirme Sürecinde Kullanımına İlişkin Görüşler

\begin{tabular}{|c|c|c|}
\hline Kodlar & Kod sıklı̆ğ & Farklı katılımcı sayısı \\
\hline Biçimlendirici değerlendirme olanağ & 36 & 13 \\
\hline Kolay kullanım olanağ & 24 & 12 \\
\hline Değerlendirmeyi kolaylaştırma & 29 & 10 \\
\hline Veri analizi & 20 & 10 \\
\hline Zamandan tasarruf & 19 & 13 \\
\hline Daha çok soru çözme olanağı & 3 & 2 \\
\hline \multicolumn{3}{|c|}{$\begin{array}{l}\text { Tablo 3'e göre çalışmaya katılan } 15 \text { öğretmen adayından 13'ü özellikle biçimlendirici } \\
\text { değerlendirme açısından Kahoot! ve Plickers'ın olumlu yönde katkı sağladığını belirtmişlerdir. } \\
\text { Öğretmen adaylarının birçoğu öğrencilerin öğrenme eksiklerini hızlı bir biçimde belirleme ve } \\
\text { anında düzeltme açısından yazılımları olumlu bulduklarını ifade etmişlerdir. K11 katılımcısının } \\
\text { bu konudaki görüşü şu şekildedir: }\end{array}$} \\
\hline
\end{tabular}

K11: Bu yazıllmlar ögrencilerin eksiklerini daha hızlı tespit edip giderilmesinde kullanilabilir.

Katılımcılardan 12'si yazılımların matematik öğretiminin biçimlendirici değerlendirme sürecinde kolay bir şekilde kullanılabileceğini belirtmişlerdir. Özellikle Plickers yazılımının internete bağlı akıllı bir cep telefonu aracılığı ile biçimlendirici değerlendirmede kolay bir biçimde kullanılabilmesi vurgulanmıştır. Buna yönelik K5 katılımcısı görüşünü şu şekilde açıklamıştır:

K5: Bu yazllım (Plickers) matematik dersinde kullanımına çok uygundur. Çünkü bu uygulama sinifta sadece bir telefon ile uygulanabilir."

Veri çözümlemeleri sonucunda kullanılan yazılımların öğretmenlere değerlendirme yapma noktasında kolaylık sağladığı belirlenmiştir. Dokuz katılımcının dile getirdiği bu hususa ilişkin 
K6 katılımcısı bunu “...değerlendirme sonuçlarını basitleştirip, yorumlanabilir hale getirmesi açısından beğendim. Ayrıca bir eğitimcinin kolay bir şekilde yorumlayabileceği bir değerlendirme süreci oluşturur. " şeklinde açıklamıştır.

Ölçme sonuçlarından elde edilen verilerin analizi, öğretmen adaylarının sıklıkla ifade ettiği bir diğer koddur. $\mathrm{Bu}$ uygulamaların gerek madde bazında gerekse öğrenci bazında önemli istatistiksel veriler sunması ve bu veriler ışığında öğrenme eksiklerinin tespit edilerek gerekli önlemlerin alınabilmesi bu durumun temel sebeplerinden olduğu görülmüştür. Bu noktada K1 katılımcısı "Öğretmen öğrencilere bunu uyguladı̆̆g zaman, hangi öğrencinin hangi soruyu yanlış yaptığını, en çok yanlış yapılan soruyu, sinıf ortalamasın ayrıntılı bir şekilde görür.” şeklinde görüş bildirmiştir.

Biçimlendirici değerlendirmenin geleneksel yöntemlerle yapılmasının önemli ölçüde zaman alması öğrenme öğretme sürecinde önemli sorunlardan biridir. Bu çalışmada kullanılan yazılımların biçimlendirici değerlendirmede zamandan tasarruf bakımından önemli avantajlar sağladığı ifade edilmiştir. Katılımcılardan 13 tanesi bu durumu destekler biçimde açıklamalar yapmışlardır. K10 katılımcısı bu durumu "Öğretmenin kisa sürede ölçme değerlendirme yapmasını sağlar." biçiminde ifade etmiştir.

Biçimlendirici değerlendirme sürecinde sınıf içinde çok sayıda soru çözme olanağı, öğretmenin öğrenciler ile ilgili daha fazla gözlem yapmasına fırsat sunabilir. Ayrıca konuların anlaşılıp anlaşılmadığının belirlenmesinde öğretmene yardımcı olabilir. Çalışmada iki katılımcı (K2, K10) özellikle Plickers ile ilgili "Kısa sürede daha çok soru çözümünü sağllyor.” şeklinde görüş bildirmiştir.

Kahoot! ve Plickers yazılımlarının biçimlendirici değerlendirmeye yönelik olumlu katkılarının yanı sıra öğretmen adayları bu yazılımların öğrenme ve öğretme sürecinde kullanımına ilişkin olumlu yönde görüşleri Tablo 4'de verilmiştir.

Tablo 4. Kahoot! ve Plickers'ın Öğrenme ve Öğretme Sürecinde Kullanımına İlişkin Görüssler

\begin{tabular}{lll}
\hline Kodlar & Kod sıklığı & Farklı katılımcı sayısı \\
\hline Oyunlaştırma & 34 & 14 \\
Öğrenmeye katkı & 4 & 4 \\
Sinıf içi etkileşim & 2 & 2 \\
\hline
\end{tabular}


Kahoot! ve Plickers yazılımları biçimlendirici değerlendirmeye katkı sunma amacı ile kullanılabilen araçlar olmakla birlikte, öğretmen adayları bu araçların sınıf içi ders etkinliklerinde kullanımlarının dersi oyunlaştırdığını, öğrenmeye katkı sağladığını, sınıf içi etkileşimi ve dersin verimini artırdığını vurgulamışlardır.

Verilerin çözümlemesinde katılımcıların tamamına yakını bu yazılımların ders sürecini oyunlaştırdığını belirtmişlerdir. Özellikle Kahoot! uygulamasında soruyu hızlı ve doğru yanıtlayanların daha yüksek puan alması dersin bir yarışma havasında işlenmesini sağlamaktadır. Katılımcılar bunun dersi eğlenceli hale getirdiğini ve dersi oyunlaştırdığını vurgulamışlardır. Buna yönelik bazı katılımcıların görüşleri şu şekildedir:

K1: Öğretmen, öğrenciye matematik sorusu sorduğu zaman yarış içerisine girip sonucu bulmaya çalışacaklar.

K5: Matematik dersi öğrenciler için sıkıcı geçer. Bu uygulama (Kahoot!) sayesinde dersler daha eğlenceli geçmektedir.

Ayrıca katılımcılar bu tür yazılımların öğrencilerin öğrenme sürecine olumlu katkıları olacağını vurgulamışlardır. Örneğin K14 katılımcısı yazılımları "Öğrencinin ögrenmesine ciddi katkı sağlayacağına inanıyorum." şeklinde değerlendirirken; K4 katılımcısı öğrenme öğretme sürecinin oyunlaştırılmasının öğrenmeye katkı sunacağını "Öğrenciler dersi oyun şeklinde işleyerek daha iyi ögrenirler" biçiminde belirtmiştir.

Yazılımları öğrenme öğretme sürecinde kullanmanın sınıf içi etkileşime olumlu katkı sunması diğer bir bulgudur. $\mathrm{Bu}$ hususu $\mathrm{K} 6$ "Kartlarla sinırlı süreyle ve de bireyler arası diyaloglar sayesinde gayet eğlenceli bir öğrenme süreci yaratır" şeklinde ortaya koymaktadır. Benzer şekilde yazılımların matematik öğretiminde kullanılmasını K9 "Derste (sınıf içi) olan aktiviteyi (etkileşim) artırıcı bir rol oynar." şeklinde sınıf içi etkileşim ortamını canlandırdığını ifade etmiştir. Öğretmen adaylarının Kahoot! ve Plickers yazılımlarının matematik öğretiminde biçimlendirici değerlendirme sürecinde kullanılmasına yönelik tutumları Tablo 5 'te verilmiştir. 
Ege Eğitim Dergisi 2017 (18) 2: 602-626

Matematik Öğretiminin Biçimlendirici Değerlendirme Sürecinde Kahoot! ve Plickers Uygulamalarının ...

Tablo 5. Matematik Öğretiminin Biçimlendirici Değerlendirme Sürecinde Kahoot! ve Plickers Kullanımına Yönelik Tutum

\begin{tabular}{lll}
\hline Kodlar & Kod sıklı̆̆ & $\begin{array}{l}\text { Farklı katılımcı } \\
\text { sayısı }\end{array}$ \\
\hline Eğitimde teknoloji kullanımına yönelik olumlu & & \\
$\quad$ tutum sağlama & 33 & 15 \\
Motivasyonu arttırma & 21 & 8 \\
Derse katılımı arttırma & 15 & 7 \\
Yaygınlaştırma & 5 & 4 \\
\hline
\end{tabular}

Öğretmen adaylarının tamamı çalışmada kullanılan yazılımların matematik öğretiminin biçimlendirici değerlendirme sürecinde teknoloji kullanımına ilişkin tutumlarını olumlu yönde etkilediğini belirtmişlerdir. Birçok öğretmen adayı bu yazılımları tanımadan önce matematik öğretiminde biçimlendirici değerlendirme sürecinde teknoloji kullanımının sınırlı olduğunu düşünürken, yazılımların tanıtılması ve uygulamalardan sonra görüşlerinin değiştiğini ifade etmişlerdir. Özellikle eğitimde teknoloji entegrasyonuna yönelik tutumlarının önem, gereklilik, yarar ve verimlilik bağlamında olumlu olduğu görülmüştür. Bununla ilgili katılımcılardan bazıları şu şekilde görüş belirtmiştir:

K1: Matematik öğretimi sürecinde teknolojinin kesinlikle kullanılmasl gerektiğini düşünüyorum.

K4: Bu programları tanımadan önce matematik dersi için teknoloji kullanmaya sıcak bakmıyordum. Bu programları tanıdıktan sonra kullanacă̆ımı düşünüyorum.

Çalışmada ön plana çıkan bir diğer bulgu da bu yazılımların motivasyon arttırmaya yönelik olduğudur. Öğretmen adayları yazılımların özellikle dikkat çekmeye, derse olan ilgiyi ve motivasyonu arttırmaya yardımcı olduğunu ifade etmişlerdir. Bu durumu destekleyen katılımeı görüşlerinden bazıları şunlardır:

K15: Bu uygulamanın öğrencinin dikkatini çekmede daha etkili olduğunu düşünüyorum.

K14: Öğrencinin de motivasyonu ve ilgisi açısından olumlu programlar olduğunu düşünüyorum.

Öğretmen adaylarının 7'si bu yazılımların öğrencileri teşvik ederek derse katılımlarını arttırdığını belirtmişlerdir. Aynı anda tüm öğrencilere yönelik sorular sorulması ve tüm öğrencilerden yanıt 
beklenmesi katılımı artıran nedenler arasında gösterilmiştir. Bununla ilgili katılımcı görüşlerinden bazıları şu şeklidedir:

K9: (Kahoot!) Öğrencilerin derse katılımını artırır. Onları derse teşvik eder.

K13: (Plickers) öğrencilerin hepsinin derse katılmasını sağlamak açısından faydalı. Çalışmada ele alınan yazılımların birçok olumlu yönünü vurgulayan katılımcılar bu tür uygulamaların yaygınlaştırılarak daha geniş kitlelere ulaşılması gerektiğini söylemişlerdir. Buna örnek olarak K4'ün görüşü şu şekildedir: “Bu programların kullanımı çok fazla yaygın değildir. Öğretmenlere bu programları tanıtıp, uygulamalarını săglamaya yardımcı olmalıyız. Yani ĕgitimde bu programların yaygın bir şekilde kullanılmasını sağlamalıyız."

Kahoot! ve Plickers'ın matematik öğretiminde biçimlendirici değerlendirilmede kullanılmasıla öğretmen adaylarının teknoloji kullanma becerilerinin geliştiği nitel verilerde ortaya çıkmıştır. Öğretmen adaylarının buna yönelik görüşleri şu şekildedir:

K2: Teknolojiyi daha yararlı bir şekilde kullanmamı să̆ladı.

K11: Daha önce teknolojiyi matematik ile ilişkilendiremiyordum. Teknoloji kullandığımda dersteki hâkimiyeti kaybedeceğimi ve zaman kaybı olduğunu düşünüyordum. Fakat bu uygulamalar ile tanışınca daha etkili uygulamalar yapıp daha hızlı sonuçlar (ölçme -değerlendirme) aldığımı gördüm. Bence her ögretmenin bu uygulamaları bilip uygulamalı.

K14: Matematik öğretiminde teknolojiyi kullanma konusunda daha yeterli hissediyorum.

K2, K11 ve K14'ün görüşlerine bakıldığında, Kahoot! ve Plickers yazılımlarının matematik öğretiminin biçimlendirici değerlendirmede kullanılmasıyla öğretmen adaylarının teknoloji becerilerinin yanında, teknolojik alan bilgisi ve teknolojik pedagojik bilgilerinin de desteklendiği söylenebilir.

Matematik öğretmeni adayları Kahoot! ve Plickers yazılımlarının matematik öğretiminin biçimlendirici değerlendirme sürecinde kullanılmasına yönelik birçok olumlu görüş bildirmekle beraber bu yazılımlarla yaptıkları uygulamalar sonrasında yazılımların çeşitli sınırlılıkları olduğunu da belirlemişlerdir. Tablo 6'da bu sınırlılıklara yönelik görüşler yer almaktadır. 
Tablo 6. Kahoot! ve Plickers'ın Sinırlılıklarına Yönelik Görüşler

\begin{tabular}{lll}
\hline Kodlar & Kod sıklı̆̆ı & $\begin{array}{l}\text { Farklı katılımcı } \\
\text { sayısı }\end{array}$ \\
\hline Teknoloji alt yapı gerektirme & 14 & 8 \\
Soru hazırlama & 6 & 3 \\
Veri analizleri karmaşık & 2 & 2 \\
Soru çözme sürecinin belirlenememesi & 2 & 2 \\
Sınırlı soru türünü desteklemesi & 1 & 1 \\
\hline
\end{tabular}

Tablo 6'ya göre bu yazılımların matematik öğretiminin biçimlendirici değerlendirme sürecinde kullanımına yönelik çeşitli sınırlılıkları bulunmaktadır. Özellikle teknolojik alt yapı gerektirmesi bu sınırlılıkların başında gelmektedir. Veriler ayrıntılı incelendiğinde Kahoot! yazılımının öğrencilerde akıllı telefon, tablet ya da bilgisayar gerektirmesi, teknolojiye erişim koşulları bağlamında önemli bir sınırlılık olarak görülmüş̧ür. Bu durumu K4 "Bu programin (Kahoot!) tek bir zaylf yönüne bakarsak tüm öğrencilerin teknolojiye erişimi olmasıdır. Günümüzde teknolojiyi kullanamayan çok öğrenci vardır." şeklinde ifade ederken K5 de benzer şekilde "Bunların yanında her sinıf ortamı bu uygulama (Kahoot!) için uygun değildir belki de en büyük sinırlıllğıdır bu yazılımın." ifadesi ile teknoloji olanağına sahip olmayan sinıflarda uygulamanın zorluğundan bahsetmiştir.

$\mathrm{Bu}$ yazılımları kullanan öğretmen adayları soru hazırlama bakımından harf sınırı olması "K4: Kahoot'ta harf sinırı olduğundan uzun sorularl yazamayabiliriz.", veri analizlerinin karmaşık olması "K14: Plickers ve Kahoot!'un veri analizleri biraz karmaşık daha anlaşıllı bir analiz yapılabilir.", soru çözme sürecinin belirlenememesi "K5: Matematikte soru çözerken nerede yanlış yaptığını göremiyorsunuz." ve yazılımların sınırlı soru türünü desteklemesi "K5: sadece çoktan seçmeli soruları içermekte" gibi sınırlılıkları olduğunu ifade etmişlerdir.

\section{Sonuç ve Tartışma}

Araştırma sonucunda öğretmen adaylarının bu yazılımların biçimlendirici değerlendirme sürecinde kullanımına dair birçok önemli noktaya işaret ettikleri tespit edilmiştir. Özellikle matematik dersinde öğretim süreci devam ederken biçimlendirmeye yönelik değerlendirme yaparak öğrenci eksiklerini tespit edip bu eksikleri gidermenin matematik öğrenmeye büyük katk1 sağlayacağ1 düşünülmektedir. Nitekim Erktin ve Nazlıçiçek (2002) biçimlendirici değerlendirmenin matematik tutumuna olumlu bir şekilde etki ettiğini belirtmişlerdir. Özçelik 
(2010) ise öğretme-öğrenme sürecinde oluşan öğrenmelerin adım adım izlenmesi ve her adımda görülen eksiklerin bir sonraki adımdan önce tamamlanması gerektiğini belirtmiştir. Değerlendirme ile ilgili ayrıntılı raporlamalar öğretmen için, öğrencilerin ve sınıfın gelişimini hızlı bir şekilde izlemeye olanak sağlamaktadır (Stacey ve Wiliam, 2013). Bu bakımdan söz konusu yazılımlar özellikle öğretim sürecinde hızlı bir şekilde dönüt vermeleri ve bunun neticesinde belirlenen eksikleri gidermeye firsat sunmaları bakımından biçimlendirici değerlendirme amacına hizmet noktasında büyük önem taşımaktadır. Bununla beraber bu uygulamalar ile biçimlendirici değerlendirme çok daha kısa sürede yapılarak dönütlerin daha hızlı ve etkili olması sağlanmaktadır. Anında dönüt verilerek öğrencilerin daha iyi öğrenmeleri sağlanabilir ve olası kavram yanılgılarının önüne geçilebilir.

Araştırma sonuçlarına göre Kahoot! ve Plickers yazılımları öğrenme öğretme sürecine önemli bir katkı sunmuştur. Yazılımların oyunlaştırma özelliğinin öğrenme öğretme sürecinde öğrenci etkileşimini ve katılımını arttırdığı ortaya çıkmıştır. Nitekim, McCabe'in (2006) bu tür uygulamalarda öğrencinin yanttlama noktasında kendini zorunlu hissetmesinin aktif katılımı artırdığı bulgusu bu çalışmanın sonuçlarıyla örtüşmektedir. Araştırmanın diğer bir sonucuna göre Kahoot! ve Plickers uygulamalarının öğretmen adaylarının matematik öğretiminde teknoloji kullanımına yönelik olumlu tutum geliştirmeye yardımcı olduğu belirlenmiştir. Ayrıca öğretmen adayları bu uygulamaların öğrencilerin motivasyonunu arttıracağını ve derse katılımlarına olumlu etki edeceğini ifade etmişlerdir. Eğitimde etkili teknoloji entegrasyonu öğretmenlerin öğrenme ve öğretme sürecine yönelik olumlu inançlarına bağlıdır (Altun, 2002; Mumtaz, 2000). Bu bağlamda olumlu tutumların gelişmiş olması gelecekte öğretmen adaylarının okullarında teknoloji entegrasyonu noktasında dirençli olmalarını engelleyebilir ve bu durum eğitimde teknoloji entegrasyon kültürü haline dönüşebilir (Kopcha, 2010). Kahoot! ve Plickers yazılımları öğrenci yanıt sistemi (ÖYS) ya da dinleyici yanıt sistemleridir. Mobil teknolojilerin gelişmesiyle cep telefonu ve tabletlere kurulan uygulamalar sayesinde yaygınlaşmıştır. Alan yazında öğrenci yanıt sistemleri ile ilgili yapılan araştırmalarda da bu uygulamaların öğrencilerin derse yönelik ilgilerini, sınıf içi etkileşimi ve derse katılımı arttırdığı belirlenmiştir (Fortner-Wood, Armistead, Marchand ve Morris, 2013; Hunsu, Adesope ve Bayly, 2016). Bununla birlikte Landrum (2015) öğrencinin derse katılımını sağlamak için ÖYS'lerin pedagojik hedefler dikkate alınarak planlı ve uygun biçimde kullanılması gerektiğini vurgulamıştır. $\mathrm{Bu}$ nedenle, öğretmen adayları ile 
gerçekleştirilen bu uygulamalar olumlu tutumlarla birlikte eğitim teknolojisi entegrasyonu becerisi kazanmaya öncülük edebilir.

Bilgisayar destekli matematik öğretimi dersi kapsamında Kahoot! ve Plickers kullanan katılımcılar eğitimde teknoloji entegrasyonu becerilerinin geliştiğini ifade etmiştir. Katılımcılar teknoloji kullanım becerisi geliştirmenin yanı sıra özellikle teknolojiyi matematik öğretiminde amaca uygun kullandıklarını ifade etmişlerdir. Teknoloji kullanım becerisi geliştirme eğitimde etkili teknoloji entegrasyonu için önemli bir ön koşuldur (Ertmer, 2001). Bu beceri TPAB becerisinin gelişmesinde hızlandırıcı bir rol oynamaktadır (Niess, 2015). Öğretmen adaylarının eğitimde teknoloji entegrasyonunu sağlamaları için onlara öğretim elemanları tarafından yeterli gözlem olanağı ve uygulamalı deneyimler sunulmalıdır. Bu çalışma nitel bulgularda görüldüğü üzere öğretmen adaylarının teknolojiyi pedagojik bir çerçevede kullanmalarına olumlu katkılar sunmuştur. Bu bağlamda, Kahoot! ve Plickers uygulamalarının öğretmen adaylarının teknolojik pedagojik alan bilgilerini geliştirmeye yardımcı olduğu söylenebilir.

Kahoot! ve Plickers gibi ücretsiz, kullanımı yaygın daha az donanıma bağlı yazılımlar maliyet açısından yaşanabilecek sınırlılığı ortadan kaldırmaktadır. Özellikle Plickers'ın sadece bir cep telefonuyla uygulanabilmesi bu konuda bir üstünlük sağlamaktadır. Ancak Kahoot!'un hem uygulayıcı hem de öğrenciler için teknoloji gerektirme zorunluluğu bu çalışmada da ortaya çıkan önemli bir sınırlılık olarak belirlenmiştir.

Sonuç olarak, matematik öğretmeni adaylarının Kahoot! ve Plickers'1 uygulamalarına yönelik görüşlerine göre, bu yazılımların matematik öğretiminin biçimlendirici değerlendirme sürecinde kullanılmasında ayrıntılı veri analizi sunması, zamandan tasarruf sağlaması, derse katılımı arttırması, dersi oyunlaştırması ve eğitimde teknoloji entegrasyonu yeterliği sağlaması bakımından bir çok olumlu katkıları olduğu ortaya çıkmıştır. Genel anlamda bu yazılımlarla ilgili olumlu görüşlerin vurgulandığı bu çalışmada, Kahoot!'un teknolojik alt yapı gerektirmesi önemli bir sinırlılık olarak görülmektedir. Bu sonuçlar bağlamında Kahoot! ve Plickers'ın matematik öğretiminin biçimlendirici değerlendirme sürecinde kullanılması, öğretmen adaylarının yetiştirilmesinde ve öğretmenlerin hizmet içi eğitimlerinde uygulamalı olarak ele alınması önerilmektedir. Bu tür uygulamaların derslerde nadiren kullanıldığı göz önüne alındığında, genel anlamda eğitim süreçlerinde Kahoot! ve Plickers gibi yazılımların farklı öğretim düzeylerinde yaygınlaştırılmalı ve öğretmenler bu konuda bilinçlendirilmelidir. Kahoot! ve Plickers 
Ege Eğitim Dergisi 2017 (18) 2: 602-626

Matematik Öğretiminin Biçimlendirici Değerlendirme Sürecinde Kahoot! ve Plickers Uygulamalarının ... 619

yazılımlarının farklı düzeylerdeki öğrencilere katkısı nicel ya da karma yöntemlere dayalı olarak incelenebilir. 


\section{Kaynakça}

Altun, A. (2002). Öncelikler ve beklentiler: İngilizce öğretmen adaylarının bilgisayar kullanma seviyeleri ve önceliklerinin belirlenmesi. Abant İzzet Baysal Üniversitesi Eğitim Fakültesi Dergisi, 4,1-16.

Atılgan, H. (2011). Değerlendirme ve not verme. İçinde H. Atılgan (Ed.). Eğitimde ölçme ve değerlendirme (s. 349-395). Ankara: Anı Yayınc1lık.

Baki, A. (2002). Bilgisayar destekli matematik. İstanbul: Ceren Yayın Dağıtım.

Baki, A. (2008). Kuramdan uygulamaya matematik eğitimi (4. Baskl.). Ankara: Harf Eğitim Yayincilik.

Baykul, Y. ve Tertemiz, N. (2004). İlköğretim birinci, ikinci ve üçüncü sınıf matematik programı üzerine bir değerlendirme. Eğitim ve Bilim, 29(131), 40-49.

Baylor, A. L. ve Ritchie, D. (2002). What factors facilitate teacher skill, teacher morale, and perceived student learning in technology-using classrooms? Computers \& Education, 39(4), 395-414.

Black, P. ve Wiliam, D. (2010). Inside the black box: Raising standards through classroom assessment. Phi Delta Kappan, 92(1), 81-90.

Bull, S., Jackson, T. J. ve Lancaster, M. J. (2010). Students' interest in their misconceptions in first-year electrical circuits and mathematics courses. International Journal of Electrical Engineering Education, 47(3), 307-318.

Emenalo, S. I. (1984). Mathematics phobia: Causes, treatment and prevention. International Journal of Mathematical Education in Science and Technology, 15(4), 447-459.

Erktin, E. ve Nazlıçiçek, N. (2002). Illköğretim matematik öğretmenleri için klsaltılmış matematik tutum ölçeği. V. Ulusal Fen Bilimleri ve Matematik Eğitimi Kongresi. http://old.fedu.metu.edu.tr/ufbmek-5/b_kitabi/PDF/Matematik/Poster/t194.pdf adresinden elde edildi. 
Ersoy, Y. (2005). Matematik eğitimini yenileme yönünde ileri hareketler-I: Teknoloji destekli matematik öğretimi. The Turkish Online Journal of Educational Technology, 4(2), 51-63.

Ertmer, P. A. (2001). Responsive instructional design: Scaffolding the adoption and change process. Educational Technology, 41(6), 33-38.

Fortner-Wood, C., Armistead, L., Marchand, A. ve Morris, F. B. (2013). The effects of student response systems on student learning and attitudes in undergraduate psychology courses. Teaching of Psychology, 40, 26-30.

Ginsburg, H. P. (2009). The challenge of formative assessment in mathematics education: Children's minds, teachers' minds. Human Development, 52(2), 109-128.

Herzig, A. H. (2002). Where have all the students gone? Participation of doctoral students in authentic mathematical activity as a necessary condition for persistence toward the PH.D. Educational Studies in Mathematics, 50(2), 177-212.

Howell, D. D., Tseng, D. C. ve Colorado-Resa, J. T. (2017). Fast Assessments with Digital Tools Using Multiple-Choice Questions. College Teaching, 65(3), 145-147.

Hunsu, N. J., Adesope, O. ve Bayly, D.J. (2016). A meta-analysis of the effects of audience response systems (clicker-based technologies) on cognition and affect. Computers \& Education, 94(2016), 102-119.

Johns, K. (2015). Engaging and Assessing Students with Technology: A Review of Kahoot!. Delta Kappa Gamma Bulletin, 81(4), 89. https://www.questia.com/library/journal/1P33787386771/engaging-and-assessing-students-with-technology-a. adresinden elde edildi.

Kazu, İ. Y. ve Yavuzalp, N. (2008). Öğretim yazılımlarının kullanımına ilişkin öğretmen görüşleri. Ĕgitim ve Bilim, 33(150), 110-126.

Kopcha, T. J. (2010). A systems-based approach to technology integration using mentoring and communities of practice. Educational Technology Research and Development, 58(2), 175190. 
Landrum, R. E. (2015). Teacher-ready research review: Clickers. Scholarship of Teaching and Learning in Psychology, 1(3), 250-254.

López García, N.J. (2016). Evaluation and ITC in Primary Education: using Plickers to evaluate musical skills. ENSAYOS, Revista de la Facultad de Educación de Albacete, 31(2), 81-90.

McCabe, M. (2006).Live assessment by questioning in an interactive classroom. İçinde D. A. Banks (Ed.), Audience response system in higher education: Applications and cases (s. 276-288). Hershey, PA: Information Science.

McIntosh, M. E. (1997). Formative assessment in mathematics. The Clearing House: A Journal of Educational Strategies, Issues and Ideas, 71(2), 92-96.

McMillan, J. ve Schumacher, S. (2010). Research in education: Evidence-based inquiry (7th ed.). Boston: Pearson.

Mevarech, Z. R. (1983). A deep structure model of students' statistical misconceptions. Educational studies in mathematics, 14(4), 415-429.

Mumtaz, S. (2000). Factors affecting teachers' use of information and communications technology: A review of the literatüre. Journal of Information Technology for Teacher Education, 9(3), 319-342.

National Council of Teachers of Mathematics [NCTM]. (2000). Principles and standards for school mathematics. Reston, VA: NCTM.

Niess, M. (2015). Transforming teachers' knowledge: Learning trajectories for advancing teacher education for teaching with technology. In C. Angeli \& N. Valanides (Eds.), Technological Pedagogical Content Knowledge: Exploring, developing, and assessing TPCK (pp. 19-37). Nova York: Springer US.

Özçelik, D. A. (2010). Ĕ̌gitim programları ve öğretim. Ankara: Pegem Akademi Yayıncılık

Richardson, A. M., Dunn, P. K., McDonald, C. ve Oprescu, F. (2015). Crisp: an instrument for assessing student perceptions of classroom response systems. Journal of Science Education and Technology, 24(4), 432-447. 
Rosnick, P. (1981). Some misconceptions concerning the concept of variable. The Mathematics Teacher, 74(6), 418-450.

Siegle, D. (2015). Technology: Learning can be fun and games. Gifted Child Today, 38(3), 192197.

Stacey, K. ve Wiliam, D. (2013). Technology and assessment in mathematics. İçinde M. A. Clements, A. J. Bishop, C. Keitel, J. Kilpatrick, \& F. K. S. Leung (Eds.), Third international handbook of mathematics education (s. 721-751). New York, NY: Springer.

Tekin, H. (2010a). Eğitimde ölçme ve değerlendirme (20. baskı.). Ankara: Yargı Yayınevi.

Tekin, E. G. (2010b). Matematik ĕgitiminde biçimlendirici değerlendirmenin etkisi Yayımlanmamış yüksek lisans tezi, Marmara Üniversitesi, İstanbul.

Tekin, E. G. ve Özdemir, A. Ş. (2014). Effect of formative assessment on mathematics success and retention. Proceedings of International Conference on Education in Mathematics, Science \& Technology, 638-648.

Tempelaar, D. T., Kuperus, B., Cuypers, H., van der Kooij, H., van de Vrie, E. ve Heck, A. (2012). The role of digital, formative testing in e-learning for mathematics: A case study in the Netherlands. RUSC, Universities and Knowledge Society Journal, 9(1), 284-305.

Wang, A. I. (2015). The wear out effect of a game-based student response system. Computers \& Education, 82, 217-227.

Wang, C., Martin, C., Lambert, R. G. ve Pugalee, D. K. (2014, Eylül). Teacher use of formative assessment and its relationship to primary students' mathematical skills. Sözel bildiri, 12th International Conference: The Future of Mathematics Education in a Connected World. Herceg Novi, Montenegro.

Wiliam, D. (1999). Formative assessment in mathematics part 1: rich questioning. Equals: Mathematics and Special Educational Needs, 5(2), 15-18.

Yıldırım, A. ve Şimşek, H. (2011). Sosyal bilimlerde nitel araştırma yöntemleri (8. bask1.). Ankara: Seçkin Yayıncılık. 


\section{Extended Summary}

Evaluation, as an integral part of the mathematics teaching, plays an important role in mathematics learning. More than being a single test at the end of instruction, evaluation allows teachers to make instructional decisions and provides a deep and qualified learning experience to all students (National Council of Teachers of Mathematics [NCTM], 2000). Formative evaluation facilitates students in point of acquiring prerequisite skills and enables them to gain higher order thinking skills (Tekin, 2010a). Technology can be used as a formative evaluation tool in mathematics instruction in order to provide instant and individual feedback (Stacey \& Wiliam, 2013). With the use of appropriate technologies in the learning environment, student engagement can be increased and learning can easily be evaluated (Johns, 2015). Web based student response systems (SRS), which can be used with mobile devices, exemplify these technologies in point of formative evaluation (Richardson, Dunn, McDonald, \& Oprescu, 2015). Kahoot! as a gamebased online response system provides teachers a visual and detailed data source of formative evaluation (Wang, 2015). Accordingly, another software application Plickers which can be used for formative evaluation also offers real-time evaluation and is a practical tool (López García, 2016). Since formative evaluation requires extracurricular activities, it is a time-consuming process (Tekin \& Özdemir, 2014) and therefore these kinds of technologies can facilitate formative evaluation. In this regard, the purpose of the study is to examine the use of Kahoot! and Plickers in the process of formative evaluation of mathematics teaching in terms of the views of pre-service mathematics teachers.

This study was carried out by adopting a qualitative research approach. The use of Kahoot! and Plickers regarding formative evaluation was examined in detail within the context of the views of pre-service mathematics teachers. The participants of the study were 15 pre-service mathematics teachers. The participants were identified by convenience sampling (McMillan \& Schumacher, 2010). They have basic skills in using dynamic mathematics software. A questionnaire consisting of open-ended questions was used as a data collection tool. The researchers trained the participants for four weeks (16 hours) in point of using Kahoot! and Plickers. The results were examined by content analysis (Yıldırım \& Şimşek, 2011).

According to the findings of the study, 13 of 15 pre-service mathematics teachers stated that Kahoot! and Plickers contribute positively in terms of formative evaluation. Besides many of 
the pre-service teachers stated that they find the software to be positive in terms of instantly diagnosing and correcting learning deficiencies. The participants also explained that these software facilitate evaluation of mathematics. Facilitating analysis of data was another code that pre-service teachers often express. Facilitating analysis of data refers to giving statistical scores of the results both for each student and for each item. It was indicated that displaying the results in that way can enable teachers diagnosing learning deficiencies and taking required precautions in the learning and teaching process of mathematics. After all, it was stated that these software contribute to save time in formative evaluation. Pre-service mathematics teachers also emphasized that using these tools in-class activities gamifies the course, contributes to learning, enhances classroom interaction and provides a productive learning environment. Especially getting high scores based on correct answers and short responding time in Kahoot! makes a competetive learning environment. Thus, pre-service teachers highlighted that these features create an entertaining and gamified learning environment. Additionally, the participants stressed that using Kahoot! and Plickers have positive effects on their attitudes toward the use of technology in formative evaluation process. Pre-service teachers explained the positive effects especially in terms of importance, requirement, advantage, and productivity. Furthermore, preservice teachers stated that these software increase students' motivation and engagement. According to qualitative data, both pre-service teachers' technology integration skills and the development of their TPACK (Technological Pedagogical Content Knowledge) were supported by using Kahoot! and Plickers in formative evaluation process in mathematics teaching. Although using the software provide many advantages of technology integration in formative evolution, it was reported that Kahoot!'s requiring technology infrastructure such as smart phone, tablet or computer is an important limitation.

As a result of the study, instant feedback feature of Kahoot! and Plickers is of vital importance to immediately identify learning deficits and resolve them, which are of great importance in formative evaluation. In addition, formative evaluation can be conducted in a much shorter time period with these applications, making feedback faster and more effective. Another fundamental result in this study is that the software significantly contributes to teaching and learning process of mathematics. According to the participants the gamification feature of the software could increase student interaction and engagement in class activities. 
Based on the views of pre-service mathematics teachers after the training activities of Kahoot! and Plickers, these software have many positive contributions in formative evaluation process of mathematics teaching in terms of displaying detailed data analysis, benefiting of saving time, increasing engagement in the classroom, gamification of courses and providing technology integration skills in education. Considering the positive views about the software, the requirement of technological infrastructure of Kahoot! seems to be an important limitation. Within the context of the conclusions, it is suggested that using Kahoot! and Plickers in formative evaluation of mathematics teaching should be taken practically both in training of pre-service and in-service teachers. 